\title{
Does Presence of role Models at Undergraduate Training Level Impact the Choice of Specialization as Maxillofacial Surgery for Young Women Dental Graduates?: Qualitative Study and Review Of Literature
}

\author{
Taranjit Kaur $^{1}$ (D) Kavita Raghotham ${ }^{2} \cdot$ Deepa Tantry $^{3}$
}

Received: 6 December 2020/ Accepted: 24 March 2021

(c) The Association of Oral and Maxillofacial Surgeons of India 2021

\begin{abstract}
Introduction Even though dentistry is becoming a womendominated profession, this is not translating into the choosing oral and maxillofacial surgery as a specialization. Hence, this study was undertaken to analyse factors impacting the choice of specialization and what impact does presence of role models as an intervention have on the attitudes of these young women on their overall career choice decisions.

Purpose This qualitative study was undertaken with the aim of understanding and analyzing the impact of role models on the overall shift in attitude of young women graduate students towards oral and maxillofacial surgery as a specialty.

Methods Eleven women maxillofacial faculties from all over the country participated in this study conducted during the 2020 Pandemic. In this study, through the online teaching programme, the influence of women teaching faculties in the form of role models was statistically
\end{abstract}

Taranjit Kaur

tkmaxfac@gmail.com

Kavita Raghotham

kavita307@gmail.com

Deepa Tantry

tantry.deepa@gmail.com

1 Department of Oral and Maxillofacial Surgery, Government Dental College and Hospital, Guru Gobind Singh Hospital, Quarter No. C2A, Near Diamond Circle, Staff Quarters, Jamnagar, Gujarat 361008, India

2 Oxford Dental College and Hospital, Bengaluru 560068, India

3 Department of Oral and Maxillofacial Surgery, Sri Venkateshwara Dental College and Hospital, Bengaluru, India analysed on 103 attendees out of 140 who answered the survey questionnaire. The sessions were conducted on Zoom platform in the form of lectures of graduate course topics as defined by Dental Council of India. The overall attitudinal shift was then statistically analysed through Chisquare test.

Result Out of 140 students, 103 students responded to the survey questionnaire. Responses of these students were statistically analysed with Chi-square test. The $\mathrm{p}$ value $<.05$ confirmed the hypothesis that presence of role models does have an impact on the choice of specialization.

Conclusion The sample size of this was small and the period of follow-up was short, four months. In order to validate these results, larger cohort and longitudinal studies of long follow-up are needed. In spite of these drawbacks, the results of this study highlight, with the help of the literature, the important role a woman mentor positively plays in career choice and other aspects of women surgeon's professional life.

Keywords Dental students - Career choice - Attitude shift . Role model/mentors - Specialization - Oral and maxillofacial surgery

\section{Introduction}

In last few decades, dentistry has seen sea change in female-to-male ratio, in terms of candidates choosing the profession. However, this change has had little impact on specialty of oral and maxillofacial surgery, which still attracts higher male graduate candidates as compared to women, as a career choice [1]. Historically women have rejected surgical specialties as a career option [2]. Various studies in the past have attempted to understand the reasons 
behind this trend, which is detrimental for the growth of specialty, as being unable to attract young intelligent minds will eventually affect overall quality of surgical education, research and practice. Lack of interactions with women surgeons as role models during graduate training period is one of the important factors which have an impact in pursuing surgical specialty as a career. Some other factors observed are prolonged training phase, long work hours, insufficient support from the family/ partners, work-life balance [1, 3-5].

It was this observation that prompted authors to undertake present study which was an outcome of a sudden shutting down of real class rooms, due to current pandemic crisis all over the country. This offered an opportunity to bring prominent women faculties from various institutes of the country, as role models, in the specialty of maxillofacial surgery, for online lectures on various topics as mentioned in DCI syllabus, to the final-year undergraduate students through an online platform of Zoom. The majority of attendees in the classroom comprised of women dental students, as anticipated, undecided about future career options. The study was designed to investigate difference in change of attitude toward the specialization before and after attending the online educational forum with the faculties.

The main aim of the study was to establish correlation between presence of a mentor or a role model in women dental graduates life and career choice. A role model has potential to be a significant factor in determining the future career choice of young women graduates. It is an opportunity for the women maxillofacial faculties to attract talented dental graduates toward the specialty.

\section{Materials and Method}

In the month of May 2020, eleven women maxillofacial surgeons, serving as faculties in various institutes of India, with academic experience ranging from 7 years till 22 years volunteered to collaborate in this study. Final-year BDS students were informed about the platform through their respective teachers by the use of WhatsApp groups, about the inception of this platform. The online platform used for this purpose was Zoom. This platform was selected after online research and practical user-friendly experience of online interactions, as a tool of learning and teaching. The chat box option allowed the participants to share their views, doubts, other material from the web which they wished to share with the faculties, along with feedbacks. The attendees participated in this survey after giving due consent for the same.

The lecture topics were chosen from the DCI (Dental Council of India) recommended syllabus for BDS students in the country. Each lecture was presented using PowerPoint presentations and live demonstrations through models. The lectures were also attended by fellow women faculties who participated as experts on the session. After the lecture, the session was open to question and answers. The live session with interactions of faculties as experts, along with clearing of doubts, usually lasted for 45 to 80 min depending on the topic of discussion.

Lectures were taken one to two times a week and were regularly attended by 175-200 attendees, throughout the time period of sessions. Occasionally, postgraduate students benefitted from these lectures as well. There was a break-up session where out of box topic of "Medical Ethics in Dentistry" was discussed with renowned bioethicist and maxillofacial surgeon, while the session was facilitated by, an OMFS expert.

Well-known male colleagues and experts from the OMFS specialty were also invited to the forum to enhance the overall exposure and experience of attending students and make the platform gender inclusive. Before the commencement and at the end of academic session, questionnaire was given to the attending students, with their due consent for participation, using Google forms, to understand the impact of the forum on the students, and whether the availability of women role models led to shift or change in their desirability to choose maxillofacial surgery as a subject of specialization.

\section{Results}

A survey questionnaire, using Google forms, was sent to 140 participants, who were routinely attending seminars with us, out of which 103 students responded giving a total response rate of $74 \%$. Out of the 103 responses, 89 participants were females and 14 were males. The students attending these seminars were mainly from Karnataka (Raichur, Bangalore), Madhya Pradesh (Indore), Gujarat (Jamnagar, Ahmedabad). The questions were mainly framed for better understanding of the change in attitude of female students, if any, toward the subject before starting of seminars and after.

On being asked, whether before attending the seminars if attendees comprising of final-year BDS (Bachelor of Dental Surgery) students were interested in pursuing maxillofacial surgery as a specialization subject, out of 103 participants, 41 responded in affirmative. Out of these 41 responses, 33 responders were females and rest males (Fig. 1). Some of the reasons mentioned for not being inclined toward the specialization were long training /education time during and after post-graduation (21.4\%), lack of enough role models (26.7\%), work-life balance issues $(26.7 \%)$, male-dominated field and sense of gender bias 

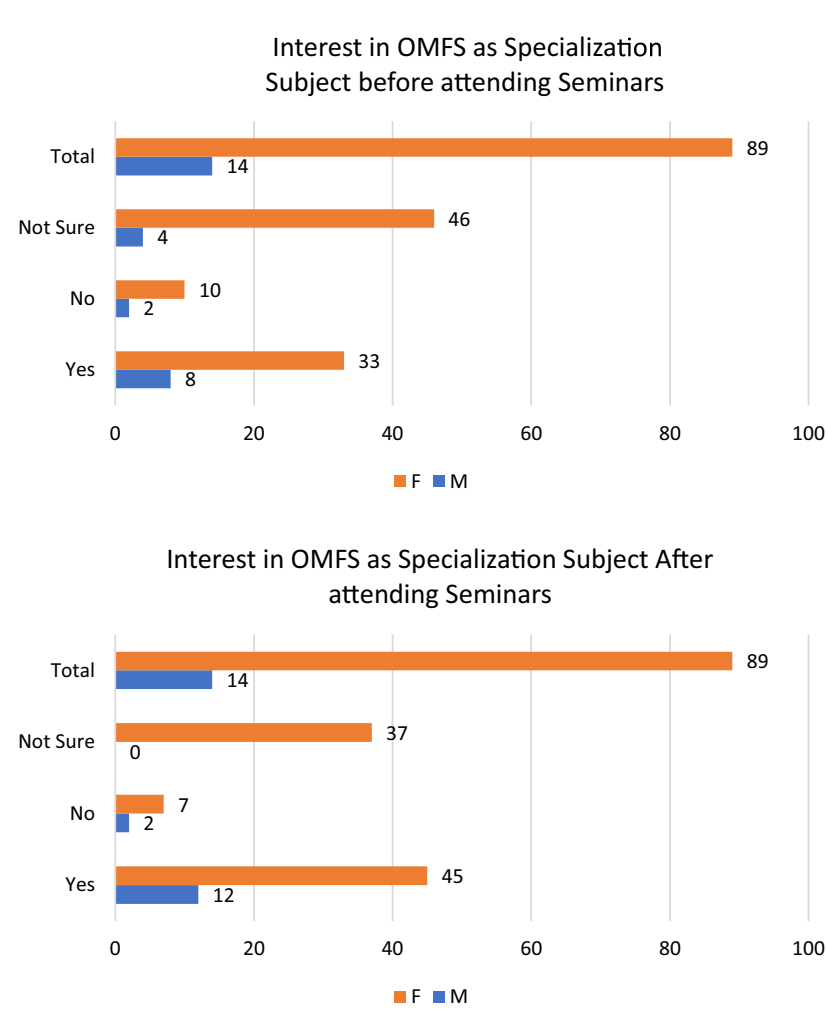

Fig. 1 a Interest in OMFS as specialization subject before attending seminars, $\mathbf{b}$ interest in OMFS as specialization subject after attending seminars

\section{Reasons for not choosing Oral and Maxillofacial Surgery as a Career Choice}

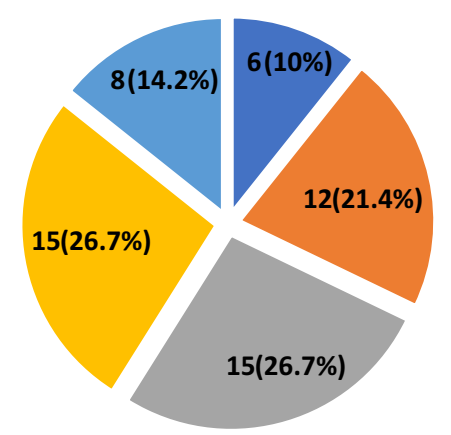

Male Dominated Field

Long Training Period

Work Life Balance

Lack of Role Models

Other Reasons

Fig. 2 Reasons for not choosing Oral and Maxillofacial Surgery as a Career Choice

(10\%) and $14.2 \%$ (8 participants) responders selected domestic/social circumstances as a reason for not feeling inclined toward a surgical specialization labeled as 'Others' (Fig. 2).

On the whole, majority participants attended between 10 and 15 lectures, with an average of $74 \%$ attending more than 10 lectures out of 17 and most of these participants benefitted in theoretical understanding of the concepts along with direct interactions with the faculties from various parts of the country. The direct interactions with the women faculties from various parts of the country influenced the final outcome. At the end of academic session, when asked how the responders feel toward oral and maxillofacial surgery, subject as a choice of specialization, the number of female responders increased from 33 to 45 from the total of 89 female attendees, 37 still remained undecided (Fig. 1).

SPSS 19 and Excel sheet were used to carry out the statistical analysis of the results. On analyzing the above data through Chi-square test, the p-value was noted to be less than 0.05 , indicating the change in perception of the participants after intervention, which is attendance of online seminars in this case. $p$-value was found to be statistically significant, thereby supporting the alternate hypothesis of presence of role models having an impact on the attitudinal shift on women graduate students toward the specialty.

\section{Discussion}

In authors experience as an educators and supported by the literature, women graduates, medical as well as dental, reject surgery as a viable choice of specialization [2]. There are various factors which affect this decision. Lack of women role models is one of the important amongst them $[3,6]$. The present study is aimed at highlighting the significant difference; a presence of positive woman role model efficiently balancing work-life and enjoying her career at the same time can make in a young woman dental graduates career choice decision, motivating her to opt for maxillofacial surgery as a specialization subject.

The current study was undertaken during the unprecedented times of pandemic caused by novel corona virus. The process which started as a salvage measure to finish BDS syllabus on time for the final examinations turned into an interesting study where women maxillofacial faculties from various parts of the country combined their classrooms over the internet and the results were favorable indicators to a hypothesis that if young women graduates are exposed to successful role models in their field at pertinent times, the possibility of them choosing the field as a future career is higher. As seen in this study, at the beginning of the seminars, when the attendees who were mostly women participants were asked through an online survey, whether they are inclined toward maxillofacial surgery as a subject of future specialization, if given a choice, significant number of participants did not favor surgical specialty for various reasons. These reasons were 
mainly stated as long training period, work-life balance issues, and the lack of suitable role models (Fig. 2). Several other studies in the past have similar findings [3, 5, 7-10]. Through this study, women educators presented an opportunity to the young women undergraduates to interact with role models and mentors and observations were made on the influence of this environment, on shift of attitudes toward the specialization. At the end of syllabus when the question was repeated to the same group of final BDS students who attended minimum 10-15 lectures throughout the three month period, hence enough time and exposure to be influenced, there was marked shift in attitude observed with number of responses answering in 'yes' increased giving us the statistically significant $\mathrm{p}$ value of .05.

It was in 1991 David Nash, Dean, College of Dentistry, University of Kentucky, in an influential article on presence of feminine mystique in Dental education, strongly recommended the urgent need for women role models in faculty positions in education and research, for women to reach their complete potential in their careers [11]. Daniel Laskin called for breaking of the glass ceiling in maxillofacial surgery in his 1993 Editorial in Journal of Oral and Maxillofacial Surgery, when he urged for active participation of institutional and organizational heads to encourage women with potential into positions of leadership and role models so that younger talent could feel confident and encouraged in pursuing maxillofacial surgery as a career [4, 12].

The work of Erwin L Linn needs a special mention, as she successfully pointed out various factors which are main social obstacles in women dentist's careers [13]. Though the article was published in 1971, the reasons for women not being able to pursue their careers to their full potential still persist, in various degrees, in different cultures. Some of the main reasons, which authors find pertinent in Indian context, are social pressure on women for marriage and relocation to different cities as per husband or partners career needs [14]. These two factors deter women from taking up surgical career, as the breaks and future uncertainty combined with work-life balance and child-bearing and rearing responsibilities mainly carried by a woman in married relationships make other specialties more easier to pursue as compared to maxillofacial surgery, as a career choice.

The presence of role models who have successfully negotiated with sociocultural factors in the past and found their careers satisfying motivates younger women into taking up a surgical career confidently, as most women in India do not feel implicit or explicit gender bias at the time of surgical training or after [14]. The main factors deterring the choice as mentioned earlier are frequent career breaks, major household work responsibility on women, and relocation for husband or partner's career needs. These are more of sociocultural factors than professional factors, as surveyed through various other studies [3, 13, 15-18].

The current study explores the use of internet technology to bring role models accessible to young women with potential for pursuing this subject as a career choice. In authors observations, use of technology as a teaching and mentoring medium has immense potential in shaping careers of younger women maxillofacial surgeons and young graduate students must explore this medium to interact and network with senior women faculties for professional and personal guidance.

There are various studies which discuss gender differences in surgical specialties in medicine as well as dentistry. The factors which lead to these differences are gender bias, long training period, and work-life balance, lack of family, and social support system [18-23]. One important finding which all studies highlight repeatedly is lack of sufficient role models and women leaders in the field. In the postmodern world, through the effective use of social media and internet-based meeting forums, the gap between role models and mentors and students can be bridged without any extravagant cost. It has also come to authors attention that since women, due to their personal life engagements travel less often as compared to their male counterparts for professional reasons, this impacts their professional visibility and networking opportunities. Through Internet technology this factor can also be overcome to a large extent where women educators and mentors can volunteer to engage with younger women graduates and offer to share their advice and knowledge and also use this platform for networking with other women colleagues from different parts of the country/world, from the comforts of their home, only with the help of good Internet connection and laptop or a smart phone, as an aid.

The use of technology to bring role models closer to young graduates so that the interest in the specialty could be enhanced is a novel and effective approach and is in tandem with the changing times of modern world, dependent on technology for most of its needs. Though the generation $\mathrm{Z}$ is more receptive to social media and Internet classrooms, the systematic investigation on long-term effectiveness and extent of change in real-life attitudes as well as decisions of career choice of women graduates attending such online meetings need to be looked into more closely and thoroughly.

\section{Conclusion}

Use of technology for purpose of daily education and mentoring was not explored until the outbreak of Novel Corona Virus pandemic 2020. Due to lockdowns all over 
the country, educators were compelled to use online platforms for educational and mentoring purposes and it is during these unprecedented times that authors realized the power of technology to bring change in attitude for young women graduates toward the specialty of oral and maxillofacial surgery. Though authors realize that the current study is significant, the time required to analyze and understand real change was insufficient and needs further investigation.

Overall senior women maxillofacial faculties are encouraged to take their position as role models and mentors for young women graduates more seriously and encourage talented, intelligent women with potential to join the specialty, by being active and consistent role models. It is only then that long-term goal of highly satisfying gender equal professional eco-systems is a possibility in near future.

Acknowledgement Authors would like to acknowledge contribution of expert on Bioethics Dr Olinda Timms and Dr George Paul (Consultant Maxillofacial surgeon and lawyer, Salem) for their session on Role of Ethics in Medical Profession : Present and future, Dr Sabine Girod (Prof of Surgery, Stanford University), for her constant inspiration during the study, Dr Krishnamurthy Bonanthaya for his session on Cleft lip and Palate, Dr Srijon Mukherjee for the session on Medical emergencies in Dental Office, Women educators from Women Maxillofacial Network, i.e., Prof Dr Reena John, Prof Dr Chitra Chakravarthy, Prof Dr Sujata Mohanty, Dr Sushmita Rajgopal, Dr Elavenil Pannasevaram, Prof Dr Divya Mehrotra, Prof Dr Mamata Aggarwal, Dr Ankita Chug, Dr Nirmal Pratap, Dr Laxmi Shetty, and Dr Arti Rao for their enthusiasm and cooperation.

\section{Declarations}

Conflict of interest The authors have no conflict of interests. No financial aid was received to conduct the study.

\section{References}

1. Puryer J, Kostova V, Kouznetsova A (2016) Final-year dental undergraduate attitudes towards specialisation. Dent J 4:26. https://doi.org/10.3390/dj4030026

2. Richardson HC, Redfern N (2000) Why do women reject surgical careers? Ann R Coll Surg Engl 82:290-293

3. Risser MJ, Laskin DM (1996) Women in oral and maxillofacial surgery: Factors affecting career choices, attitudes, and practice characteristics. J Oral Maxillofac Surg 54:753-757. https://doi. org/10.1016/S0278-2391(96)90697-7

4. Laskin DM (2001) Closing the gender gap. J Oral Maxillofac Surg 59:127. https://doi.org/10.1053/joms.2001.22011

5. Kfouri MDG, Moysés ST, Gabardo MCL, Moysés SJ (2017) Gender differences in dental students' professional expectations and attitudes: A qualitative study. Br Dent J 223:441-445. https:// doi.org/10.1038/sj.bdj.2017.810

6. Rostami F, Ahmed AE, Best AM, Laskin DM (2010) The changing personal and professional characteristics of women in oral and maxillofacial surgery. J Oral Maxillofac Surg 68:381-385. https://doi.org/10.1016/j.joms.2009.09.101
7. Shin JH, Kinnunen TH, Zarchy M, Da Silva JD, Chang BMW, Wright RF (2015) Factors influencing dental students' specialty choice: a survey of ten graduating classes at one institution. J Dent Educ 79:369-377

8. Stewart FMJ, Drummond JR, Carson L, Hoad RG (2005) A survey of dental school applicants' career intentions and the balance with family life. Br Dent J 198:713-717. https://doi.org/ 10.1038/sj.bdj.4812391

9. Kabil NS, Allam GG, Abd El-Geleel OM (2018) Motivational reason for choosing dentistry as a professional career $\&$ factors affecting specialty choice among final year dental students. Futur Dent J 4:308. https://doi.org/10.1016/j.fdj.2018.04.002

10. Nash DA (1991) The feminine mystique in dental education: A feminist's challenge. J Am Coil Dent 58:33

11. Laskin DM (1993) The Glass Ceiling of Oral and Maxillofacial Surgery. J Oral Maxillofac Surg 51:225

12. Linn E (1971) Women dentists: career and family. Soc Probl 18:393-404

13. Kaur T, Nair S (2018) A woman oral and maxillofacial surgeon of India: is she satisfied with her career choice? J Maxillofac Oral Surg 18:11-14. https://doi.org/10.1007/s12663-018-1170-8

14. Marti KC, Lanzon J, Edwards SP, Inglehart MR (2017) Career and professional satisfaction of oral and maxillofacial surgery residents, academic surgeons, and private practitioners: does gender matter? J Dent Educ 81:75-86. https://doi.org/10.1002/j. 0022-0337.2017.81.1.tb06249.x

15. Puryer J, Selby J, Layton J, Sandy J, Ireland A (2017) The association between postgraduate studies, gender and qualifying dental school for graduates qualifying from uk dental schools between 2000 and 2009. Dent J 5:11. https://doi.org/10.3390/ dj5010011

16. Burgos CM, Josephson A (2014) Gender differences in the learning and teaching of surgery: a literature review. Int $\mathrm{J}$ Med Educ 5:110-124. https://doi.org/10.5116/ijme.5380.ca6b

17. Park J, Minor S, Taylor RA, Vikis E, Poenaru D (2005) Why are women deterred from general surgery training? Am J Surg 190:141-146. https://doi.org/10.1016/j.amjsurg.2005.04.008

18. Scarbecz M, Ross JA (2007) The relationship between gender and postgraduate aspirations among first- and fourth-year students at public dental schools: a longitudinal analysis. J Dent Educ 71:797-809. https://doi.org/10.1002/j.0022-0337.2007.71.6. tb04336.x

19. Piccinato CE, de Rodrigues MLV, de Rocha LA, de Troncon LEA (2017) Characteristics of role models who influenced medical residents to choose surgery as a specialty: Exploratory study. Sao Paulo Med J 135:529-534. https://doi.org/10.1590/ 1516-3180.2017.0053030517

20. Neumayer L, Kaiser S, Anderson K, Barney L, Curet M, Jacobs D et al (2002) Perceptions of women medical students and their influence on career choice. Am J Surg 183:146-150. https://doi. org/10.1016/S0002-9610(01)00863-7

21. Marciani RD, Smith TA, Heaton LJ (2003) Applicants' opinions about the selection process for oral and maxillofacial surgery programs. J Oral Maxillofac Surg 61:608-614. https://doi.org/10. 1053/joms.2003.50091

22. Friedman PK (1992) Mentors: who are they? Where are they? Do we need them? J ent Educ 56:566-568

23. Walsh U, Meyer F (2011) Factors Influencing Career Choice of Female Surgical Trainees. Bull R Coll Surg Engl 93:1-7. https:// doi.org/10.1308/147363511x558146

Publisher's Note Springer Nature remains neutral with regard to jurisdictional claims in published maps and institutional affiliations. 